\title{
Building an Undergraduate Book Approval Plan for a Large Academic Library
}

\author{
Denise Koufogiannakis \\ Collections \& Acquisitions Coordinator \\ University of Alberta \\ Sandy Campbell \\ Acting Collections Manager for the Science and Technology Library \\ University of Alberta \\ Fred Ziegler \\ Collections Coordinator in the Humanities \& Social Sciences Library (Rutherford) \\ University of Alberta
}

\begin{abstract}
The University of Alberta Libraries (UAL), working with two book vendors, created large-scale undergraduate book approval plans to deliver new publications. Detailed selections profiles were created for many subject areas, designed to deliver books that would have been obvious choices by subject selectors. More than 5800 monographs were received through the book approval plans during the pilot period. These volumes proved to be highly relevant to users, showing twice as much circulation as other monographs acquired during the same time period. Goals achieved through this project include: release of selectors' time from routine work, systematic acquisition of a broadly based highdemand undergraduate collection and faster delivery of undergraduate materials. This successful program will be expanded and incorporated into UAL's normal acquisitions processes for undergraduate materials.
\end{abstract}

Keywords: monograph acquisitions; collection management

\section{Background}

The University of Alberta is a large academic institution serving approximately 34,000 students, 28,000 of whom are enrolled in undergraduate programs. Courses are offered in a broad array of subject areas. The University of Alberta Libraries (UAL) spends well over two million dollars on monographs each year. Historically, monograph selection has been conducted on a title-by-title basis by subject selectors. Approval plans, whereby books are automatically selected by a vendor for the library according to predefined criteria, have not been a large part of the Libraries' acquisitions strategy. Until recently, only a few small, specialized book approval plans were in place at UAL. 
In 2004-2005, UAL made several changes to its acquisitions processes; the major one being a move towards selector-based online ordering within monograph vendors' online systems. There was also a move away from the use of the integrated library system (ILS) to track expenditures, using instead the University accounting system PeopleSoft. Major vendors were reviewed and consolidated, and purchasing focused on two English language vendors, YBP Library Services (YBP) and Coutts Information Services (Coutts).

At the same time, the University was placing a renewed emphasis on undergraduate teaching and research. With a view to strengthening the undergraduate collection across all disciplines, and with an increase in the materials budget, UAL decided to dedicate a portion of this new money to a centrally managed undergraduate book approval plan. It was recognized that there were a number of standard undergraduate books that selectors would purchase, and automating this process would reduce selector workload and increase the speed with which those books were received by the Libraries. Thus began the investigation into a large scale approval plan for undergraduate books across science and technology as well as humanities and social sciences subject areas.

\section{Establishing the Plan}

A review of the literature and discussions with vendor representatives revealed no examples of large academic institutions acquiring large portions of their undergraduate collections through approval plans. The literature generally points to subject based plans (Bartolo, Ott and Wicks; Corrsin; Kamada) or those based on specific language materials (Cohen; Oddo). Other literature looks at plans for consortia (Armstrong and Nardini; Curl and Zeoli; Diedrichs), or evaluation of academic library plans in general (Brown and Forsyth; Plodinec and Schmidt). The body of existing literature informed our thinking about the type of plan we wanted, but there was no directly relevant work that targeted undergraduate students' needs via an approval plan. Hence, the Collection Development Committee at UAL proceeded to establish such a plan from scratch, working closely with vendor representatives.

Undertaking a major change in any process always involves balancing risks and benefits. With this project the anticipated risks included the potential for cost overruns, receipt of unwanted materials, receipt of duplicate materials, inability to evaluate the program effectively due to a lack of good receipt information, and the potential for alienation of subject libraries without undergraduate programs which would not receive funding from this program. The anticipated benefits included improved efficiency in selection and receipt of monographs, release of selectors' time to focus on higher level or more complex acquisitions, faster receipt of books after publication, broader subject coverage in the undergraduate collection, and a better range and more consistent coverage of new publications. As Eldredge notes, "Approval Plans should be relied upon to deliver the easily 
accessible, obvious material the library is expected to have available for use" (52).

Beginning in the spring of 2005, a group of collections staff worked with YBP and Coutts to determine parameters for the undergraduate book approval plan. Profiles had to be established for the different subject areas, costs projected, and purchases tracked. In a similar vein as Horava, "we wanted our librarians to focus most of their time on identifying and selecting the small number of titles and sources that require their expertise and knowledge, while allowing the vendor to supply a large quantity of titles from major publishers according to the established profiles" (70).

\section{Profiles}

Vendor profiles allow the library to define and specify the types of books that will be sent to the library. They include decisions about subject coverage, publication types, geographic coverage, and so on. A profile can be tailored to suit a particular library's needs. The UAL decided that there would be separate profiles for science, social sciences, and humanities, based on Library of Congress call number ranges. The Education, Law and Medical Libraries chose not to participate in the plan in the first year, and continued with their regular acquisition processes. Librarians at the H.T. Coutts Education Library wanted to wait and see how the first year pilot would work, whereas librarians at the Law and Medicine Libraries felt that their focus was not on undergraduate education and therefore they did not fit within the scope of these plans.

While the UAL's collections are very broadly based and cover all subject areas, not all areas have undergraduate programs. Profiles were developed by beginning with the complete Library of Congress classification list and then deleting subjects not taught at the undergraduate level. Examples of the subjects deleted included trades, cooking, computer hardware and software, and journalism. While these subject areas are collected, they are acquired selectively and on an as-needed basis.

Three profiles were established for the first year of the plan:

1. Science - included science, engineering, agriculture, home economics, forestry and nursing. This plan was developed in conjunction with YBP and had a price limit of \$200USD per book.

2. Social Sciences - included anthropology, political science, sociology, business and economics, psychology, and women's studies, and was also developed in conjunction with YBP. A price limit per book was set at \$125USD. 
3. Humanities - included languages and literature, drama, art, music, and religious studies. This plan was developed in conjunction with Coutts and had a price limit of $\$ 125$ USD per book.

Later in the process a separate plan was added for the Augustana Faculty Library, a campus physically removed from the rest of the University of Alberta and which requires some of the same content to be housed in their location. This profile was developed with YBP to supply monographs in a number of specific subject areas.

Since funding was finite and the UAL's materials arrive at the library shelf-ready, making it impossible to return unwanted volumes, it was important to ensure that the undergraduate book approval plan profiles had tight parameters. Nonsubject parameters were established using the standard vendor lists. Material deleted from all profiles included local U.S. material, material relating to celebrities, as well as biographies, diaries, cartoons, and reference works. In addition, specific publishers that did not meet the Library's needs were deleted from the profiles. All Canadian imprint materials were also excluded, as these are currently delivered through separate Canadiana approval plans with Coutts.

It was also essential to define the academic levels of the materials delivered through the approval plans. Readership levels assigned by vendors, which place judgment and categorize books by the level of readership for which the book is primarily intended, were used to focus our efforts on materials appropriate for undergraduate students. Initially, the criteria assigned were too specific and the Library did not receive enough materials. In the end, for the YBP profiles "Basic Academic" and "Research Academic" levels were selected. For the Coutts profile, "Upper Level Undergraduate" and "Lower Level Undergraduate" were selected. The materials being received throughout the pilot phase were monitored by spot checking receipts on-site and through monthly reports generated by the vendors. Through regular communication with selectors and vendors the profiles were revised until the materials received matched the selectors' expectations.

\section{Projecting Costs}

In order to estimate the potential cost of the programs, vendors were asked to execute test profiles against what would have been delivered in the previous year. YBP supplied a test against a three month sample and a one year estimate was extrapolated. Estimated costs were provided for both the social sciences and the science plans, with options based upon whether certain academic levels of books would be included or excluded. This estimate showed that the plan would deliver approximately 4,200 books at a cost of about $\$ 229,000$ USD. Coutts supplied an estimate of the number of books (120 books/month or 1,400 per year) that the Libraries could expect on the humanities plan. 
Based on the cost projections from the vendors, an allocation of approximately $\$ 280,000$ CAD was made to cover costs for the first year of the science, social sciences and humanities plans. An additional \$30,000CAD was allocated for the Augustana Faculty plan. It was necessary to separate the Augustana plan from the others, as many of the books acquired on this plan would be duplicates of books charged against the other plans.

\section{Evaluating the First Year}

In order to evaluate the effectiveness of the plan, the Collection Development Committee needed to determine whether or not the books being delivered on the plan were being used. All of the catalogue records had been tagged with an identifier so that the circulation information for these books could be isolated from the rest of the collection. We wanted to be able to determine the number of books catalogued and placed in the library stacks, as well as to track overall usage with circulation information focused on areas of high use as well as on the groups of patrons that were making use of these books.

In the first year of the plan (September 1, 2005 - August 31, 2006), 5,801 books were catalogued with an average of 483 books catalogued each month (Figure 1). The estimate of 4,200 titles from YBP, along with a further 1,400 from Coutts, was just slightly under the true numbers catalogued within the first year.

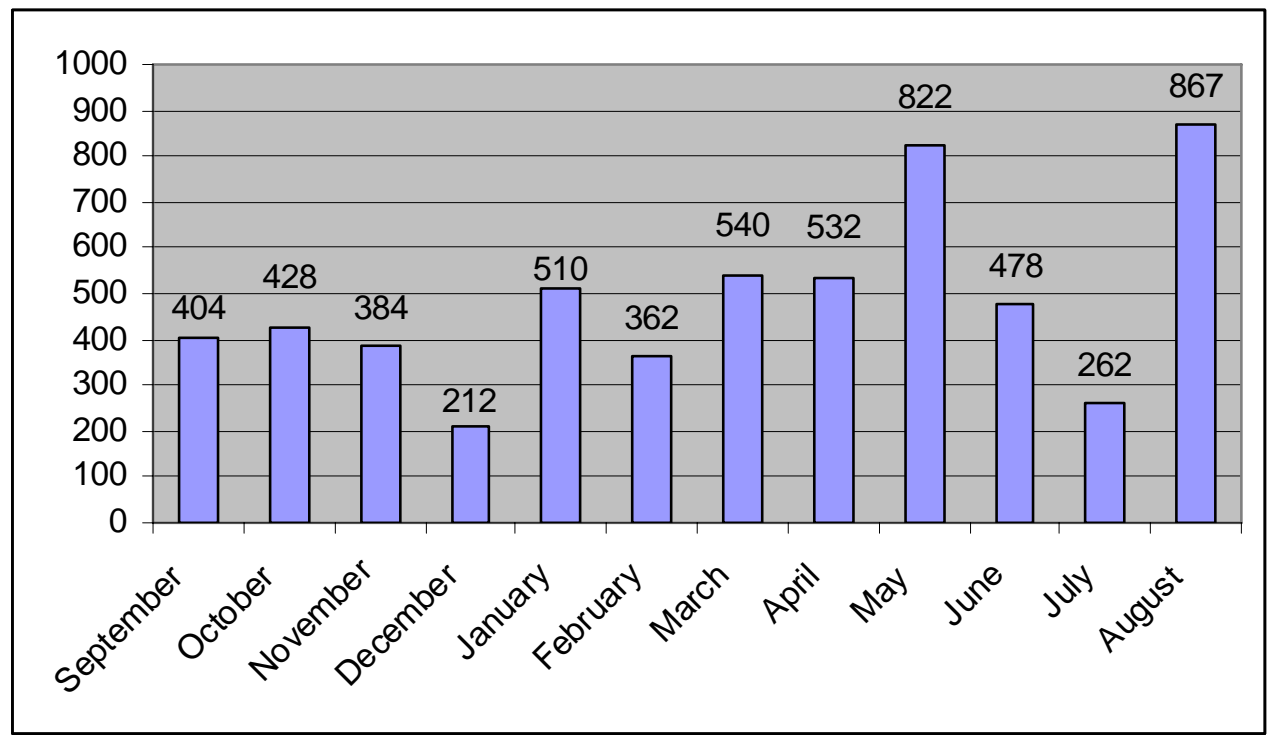

Figure 1. Undergraduate Book Approval Plan Titles Catalogued, September 2005 - August 2006.

Circulation statistics show that the titles purchased on the undergraduate book approval plan are being well used. As Figure 2 shows, between September 2005 and August 2006 there were 5,699 check-outs, 2,463 holds placed, and 3,131 renewals of books acquired through the undergraduate book approval plan. Based on total numbers of checkouts, holds, and renewals per title, the average 
use of these materials is about twice as high as for other monographs added to the catalogue during the same time period.

The circulation statistics over the months of the fall of 2006 (September November) show a marked increase in circulation for titles purchased on the undergraduate book approval plan, with an average of 1,368 checkouts occurring per month during this time period, and an added average of 819 renewals per month. This more than doubles previous months' checkouts and gives an indication of the relevance of these books during the Fall 2006 term, at the point when a critical mass of books for student use had been built.

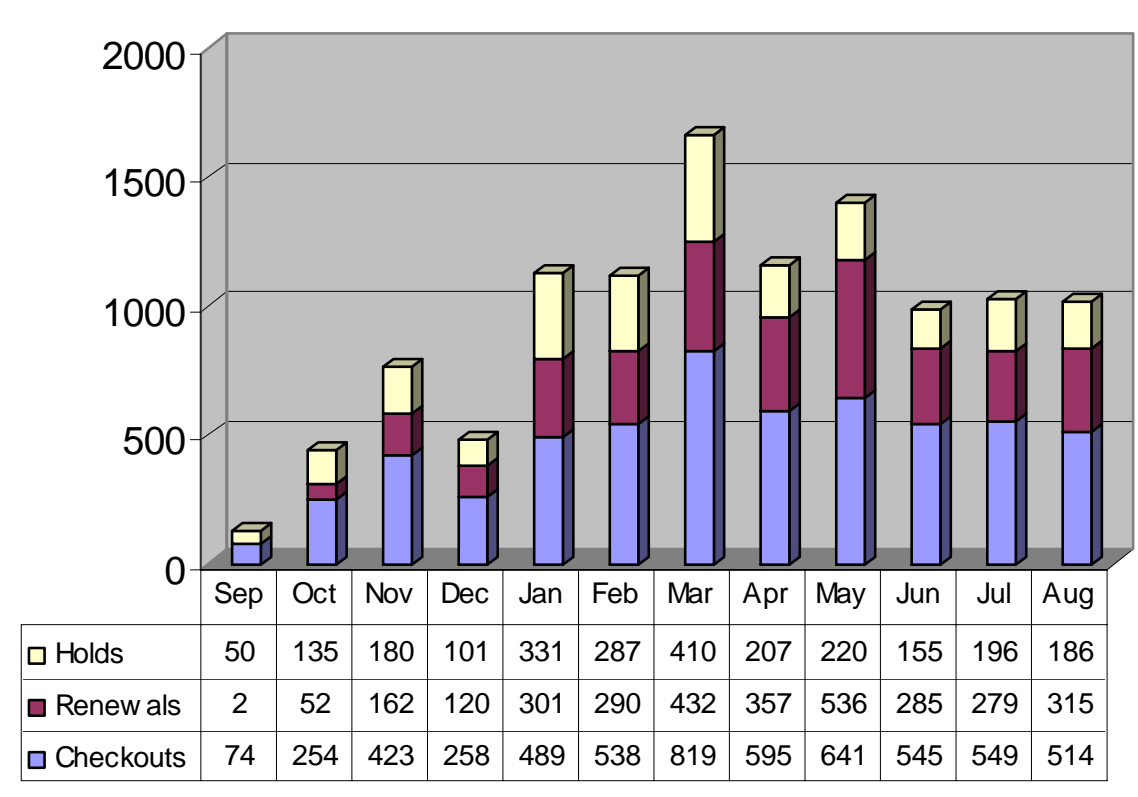

Figure 2. Circulation of materials received through the Undergraduate Book Approval Plan, September 2005 - August 2006.

The primary borrowers of the undergraduate plan books are University of Alberta undergraduate students, accounting for $31 \%$ of checkouts. University of Alberta graduate students account for $24 \%$ of checkouts. The books are also being used by faculty, staff, and members of NEOS, a central Alberta consortium of special and academic libraries.

By using an approval process to acquire a large portion of the new undergraduate materials, several goals have been achieved. First, a large portion of undergraduate materials have been acquired in a systematic way. Second, selectors' time that would have been dedicated to choosing undergraduate materials has been released. Third, the undergraduate collection has been renewed in areas where the UAL had not been systematically collecting. Fourth, based on circulation statistics, staff know that the material acquired on the undergraduate book approval plan is highly relevant. 
While staff reaction has been largely positive, there was some initial resistance from subject selectors who felt that the plan had the potential to deliver materials that were not of the quality that they would have selected. However, over the course of the pilot, subject selectors have recognized the benefits of the approval project. Many have commented that when they review their online selection slips many of the materials which they would have chosen for their subject areas have already been shipped via the approval plan. They are pleased that this is happening because the books arrive in a more timely manner and are more quickly available to library users. With the monthly reporting of receipts and the leeway to make changes to the profiles, selectors are generally satisfied with the content that is now being delivered on the undergraduate book approval plans.

\section{Next Steps}

Based on the success of this pilot project, the undergraduate book approval plan will continue to be a key source of undergraduate books in the UAL collection. In November 2006, a profile for education books was added to the social sciences plan. Over the next several months the titles sent to the H. T. Coutts Education Library will be closely monitored and changes will be made to this profile as needed.

In the future, the Collection Development Committee will consider the possibility of receiving e-books on these plans. UAL is already set up to order individual NetLibrary titles with YBP and MyiLibrary e-books from Coutts. Mirror profiles for e-books have been created, although not activated. These profiles allow staff to evaluate the content, cost, and number of e-books that would be received. In the future UAL will need to determine how e-books could be integrated into the approval process, and then decide whether this fits with the overall purchase plan for e-books.

UAL will continue to work closely with the vendors to make refinements to the profiles as needed. Approval profiles are living documents and must be regularly updated and revised as conditions change. The Collection Development Committee considers the first year of this plan to have been a success and intends to continue to move forward with similar changes to acquisitions procedures, as part of the UAL's mission to better assess and meet the needs of our library users.

\section{Works Cited}

Armstrong, K. and B. Nardini. "Making the Common Uncommon? Examining Consortial Approval Plan Cooperation." Collection Management 25.3 (2001): 87-105. 
Bartolo, Laura M., Valerie A. Ott and Don A. Wicks. "Border Crossing in a Research University: An Exploratory Analysis of a Library Approval Plan Profile of Geography." Collection Management 27.3/4 (2002): 29-44.

Brown, Linda A., and John Harper Forsyth. "The Evolving Approval Plan: How Academic Librarians Evaluate Services for Vendor Selection and Performance." Library Collections, Acquisitions, \& Technical Services 23.3 (1999): 231-77.

Cohen, Martin. Developments in Foreign Approval Buying. PMLA: Publications of the Modern Language Association of America 116.2 (2001): 392-3.

Corrsin, S.D. "Slavic Studies Approval Plans: Report on a Panel at the 1999 Annual Conference of the American Association for the Advancement of Slavic Studies." Against the Grain 12.3 (2000): 33-34.

Curl, Margo Warner, and Michael Zeoli. "Developing a Consortial Shared Approval Plan for Monographs." Collection Building 23.3 (2004): 122-28.

Diedrichs, C.P. "Designing and Implementing a Consortial Approval Plan: The OhioLINK Experience." Collection Management 24.1/2 (2000): 15-44. 
Eldredge, M. "Major Issues in Approval Plans: The Case for Active Management." Acquisitions Librarian 16 (1996): 51-59.

Horava, Tony. "A Concurrent Pilot Project Approach to Approval Plans." Library Collections, Acquisitions, \& Technical Services 30 (2006): 69-76.

Kamada, Hitoshi. "Incorporating a Japanese Material Approval Plan in a Changing Collection Development Environment at the University of Arizona." Collection Management 29.1 (2004): 3-17.

Oddo, D.J. "Creating a Greek Approval Plan at Yale." Against the Grain 12.4 (2000): 42, 44.

Plodinec, Louise, and June Breland Schmidt. "Which Worked Better for Mississippi State: Standing Orders or an Approval Plan?" Library Collections, Acquisitions, \& Technical Services 26 (2002): 439-48. 